catalogued cancer-associated mutations in patients with advanced melanoma, hoping to use the information to tailor immune cells to destroy tumours. And promising initial results were unveiled on targeting a protein called IDH2, mutations in which crop up in many different tumour types (see Nature 508, 158-159; 2014).

It has taken a massive effort to make such achievements possible. Seventeen countries have invested in sequencing cancer genomes through the International Cancer Genome Consortium (ICGC), which aims to sequence more than 25,000 samples. The largest and oldest component of that project is The Cancer Genome Atlas (TCGA) at the US National Cancer Institute (NCI) in Bethesda, Maryland, which intends to characterize 10,000 tumours.

TCGA was initially controversial, because researchers worried that the project would direct funds away from grants to individual investigators. Early results - which showed that cancer mutations were much more abundant and diverse than expected - even evoked schadenfreude in some circles (see Nature 455, 148; 2008). Criticism died down as the project bore fruit.

But TCGA is now winding down: the project ceased collecting new tissue samples last December. The ICGC, too, has virtually stopped accepting proposals for new projects. TCGA aims to complete sequencing and further characterization of its cancer samples by the end of the year. After that, a few groups will receive funding to analyse the data for the next two years. But the programme, as it existed, will cease.

Some cancer researchers have advocated that the programme should continue. Stopping now would be premature, their argument goes, because we have yet to achieve a comprehensive catalogue of cancer-causing mutations. A study published earlier this year determined that compiling a list of mutations present in at least $2 \%$ of cancers would require sequencing of about 2,000 tumours in each of at least 50 tumour types (M. S. Lawrence et al. Nature 505, 495-501; 2014). For most cancers, we are still far short of that goal.

On a more optimistic note, the end of the older projects should herald a needed transformation in the field. When TCGA and the

ICGC were launched, the technology dictated that only fresh tumour samples could be sequenced. That restriction limited researchers' ability to link sequencing data with clinical outcomes because that information might not be available until years after the sample was taken. Also, at that time, oncologists did not take more than one biopsy of a tumour from a patient, which limited studies of how tumours changed during and after treatment, and how metastases differed from primary tumours.

"The end of the older projects should herald aneeded transformation in the field."

(17.

Those hurdles have now been largely surmounted. Improved techniques allow researchers to sequence DNA collected from tissue preserved in formaldehyde and embedded in paraffin, opening the door to using banked samples with linked clinical data. And although still an uncommon practice, several clinical trials have shown that many patients are willing to submit to extra biopsies.

To replace TCGA, the NCI intends to sequence tumours from patients enlisted in some of its clinical trials. Other teams will no doubt do the same, allowing researchers to learn more about the importance of a given mutation by associating it with the response to therapy or to overall prognosis.

These changes require a new mindset. Clinical researchers will need to change consent forms for donation of tissue samples, to allow the association of clinical data with the sample. They will have to collect their samples using protocols that ensure utility not just for classical pathology but also for sequencing. Data security, always a concern when dealing with patient information, will need to be bolstered.

Nevertheless, to continue the work is a worthy undertaking. The end of TCGA also represents an opportunity for the field to balance its cancer-genomics projects more evenly between cataloguing mutations and studying their functional significance. Functional studies have had short shrift, whereas sequencing - a simple concept, and easier to communicate to policy-makers and the public — has taken the lead. Correcting that imbalance will lead to exciting discoveries for science and for patients.

\section{Practical nonsense}

\section{Downgrading practical science will impede UK students in the global workplace.}

"E quipped with his five senses, man explores the universe around him and calls the adventure Science." So wrote US astronomer Edwin Hubble in 1929, but was he right? How much should science be an exploration of the senses - as well as a test of knowledge and intellectual flexibility? Does a physics student need to peer through a telescope to grasp the enormity of the Universe? Must a potential chemist grapple with the tap of a titration flask to appreciate the subtleties of reaction synthesis? The UK government is about to take a massive - and massively misguided — gamble that they do not.

Education officials in Britain have decided to remove assessed practical work from the landmark A-level qualification, taken by students aged 16-18 and a prerequisite for university. In doing so, the officials and the school science they oversee have taken a huge step backwards. The move could see an entire generation denied the opportunity to develop an interest in the practical experience of doing science.

The Office of Qualifications and Examinations Regulation (Ofqual), which has made the change, says that such fears are overblown. Practical skills will still be tested, it says, and the results presented as a separate pass/fail mark to accompany the existing A-level letter grade. Schools will be inspected. Practical skills, Ofqual promises, will survive.

There are two problems with this. First, as institutions told Ofqual when it floated the idea last year, universities will still focus on the mark - how else will they differentiate between the thousands of applicants? Second, if the result of a practical test is seen as secondary to the overall grade, then schools will be less concerned with it. UK education has become a ruthless marketplace in which schools are judged by how well they can shift students on to the next stage. Anything that interferes with that is unlikely to be a priority. Students, especially those at poorer-performing schools, will simply be offered fewer lessons in practical science.

As John Baruch pointed out in a World View article last month, the UK change comes at a time when other nations, China chief among them, are placing increased emphasis on practical skills in schoolleaving exams (see Nature 507, 141; 2014). The United Kingdom is poised to send its science students into the global competition for scientific and technical jobs with one arm tied behind their backs.

Ofqual made its decision in the face of fierce criticism from leading scientists and science advocates. There were certainly problems with testing practical skills through coursework - long viewed by students as the soft underbelly of academic assessment - but, in this case, the proposed solution is worse. As Imran Khan, chief executive of the British Science Association, puts it: "You wouldn't dream of assessing other practical subjects - like languages, music, or design - by a written test alone, and the same should be true of science." We are back to Hubble's five senses, and the need to stimulate and extend them.

Practical experiments teach the reality of science, with all its frustra-
D NATURE.COM To comment online, click on Editorials at: go.nature.com/xhunqv tions and rewards. The real world, after all, does not always proceed smoothly. As the old joke among physics teachers goes: if an experiment smells, it is chemistry; if it moves, it is biology; and if it doesn't work, it is physics. 